\title{
A cauda equina syndrome in a patient treated with oral anticoagulants. Case report
}

\author{
J Willems MD, ${ }^{1}$ A Anné MD,${ }^{1} \mathrm{P}$ Herregods $\mathrm{MD},{ }^{1} \mathrm{R}$ Klaes $\mathrm{MD},{ }^{2} \mathrm{R}$ Chappel $\mathrm{MD}^{1}$ \\ ${ }^{1}$ Department of Physical Medicine and Rehabilitation, ${ }^{2}$ Department of Neurosurgery, \\ A.Z. Middelheim, Lindendreef 1, B-2020 Antwerp, Belgium.
}

The authors report a patient who was on oral anticoagulants because of mitral valve disease and who developed paraplegia from subarachnoid bleeding involving the cauda equina. The differential diagnosis, investigations and treatment of the cauda equina syndrome are described.

Keywords: cauda equina syndrome; anticoagulants; subarachnoid haemorrhage; mitral valve disease.

\section{Case report}

A 32 year old woman from Chile presented with a complete paraplegia. She claimed that the paraplegia had developed progressively over 8 months. Initially she had paraesthesiae in her feet, followed by progressive paresis of both legs, beginning distally, over a period of 3 months. Two months after the onset of illness she complained of bladder incontinence. There was no history of trauma or low back pain.

Clinical examination in our hospital revealed a flaccid paraplegia at L1 level, and loss of sensation from the groins to the feet, including saddle anaesthesia. The knee and ankle jerks were absent. The anal sphincter was atonic. She had an indwelling urethral catheter, and she was faecally incontinent.

Myelography and a CT scan were carried out, and a space-occupying lesion at the level of T12-L4 (Figs 1,2) was defined. Surgical exploration was done to determine the cause. A laminectomy was performed from L1 to L3. The dura mater was stretched and showed no pulsations. The dura was opened longitudinally, and a grey capsulated mass from L1 to L3 was seen which displaced the cauda equina ventrally. The capsulated mass contained fibrotic and necrotic tissue. Some of the nerve roots were located within the mass. The mass could be almost completely resected. Histological examination revealed evidence of an old haemorrhage (Fig 3). Confronted with these facts, the patient admitted that the paraplegia was sudden in onset and occurred about 8 months previously. She explained it that way, apparently hoping that a hospital admission would favour her request for political refugee status. The first symptom was sudden pain at the

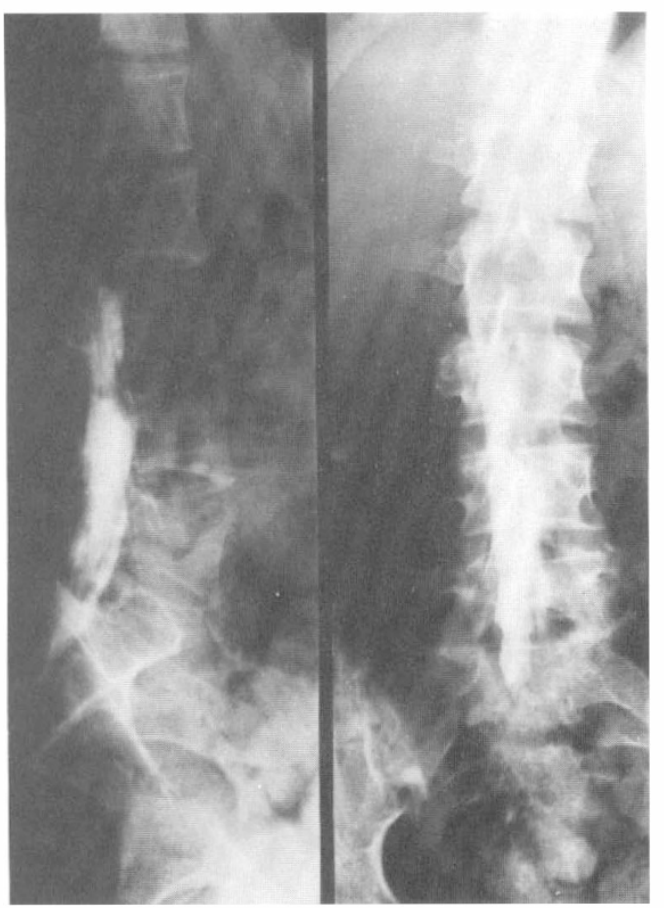

Figure 1 Myelography shows a hold up at the level of L2-L3.

thoracolumbar level of her back, like a dagger stab. She was not straining or doing anything special at that particular moment. The pain radiated to her lower limbs, and within an hour she developed complete anaesthesia and paralysis of the lower limbs. She had been taking an anticoagulant, Fenprocoumon $3 \mathrm{mg} /$ day, which had been prescribed to prevent thromboembolic 


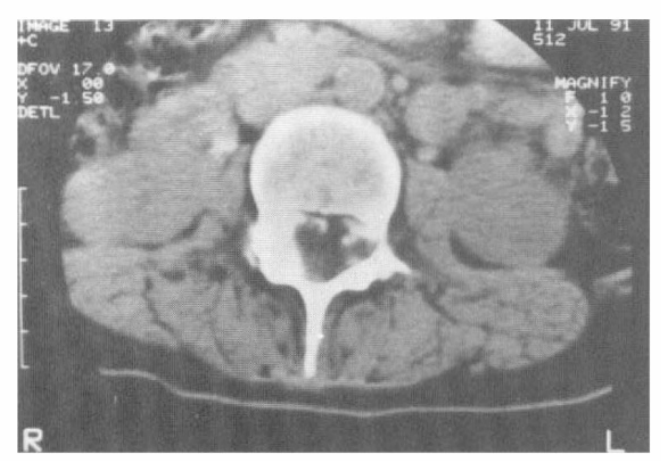

Figure 2 CT scan after myelography at the level L2. The contrast fails to fill the whole of the dural sac, and the centre remains free of contrast in an irregular fashion.

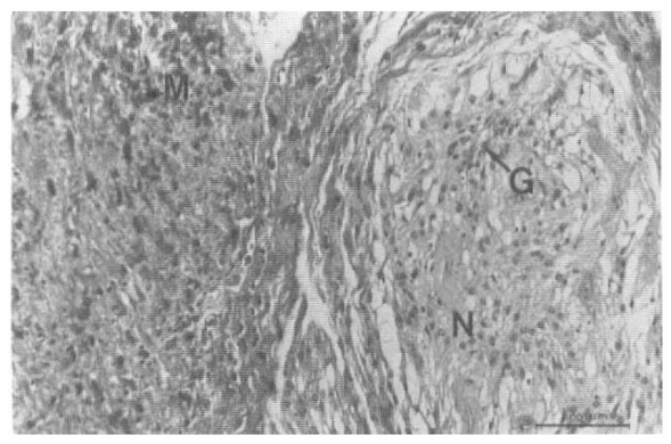

Figure $3 \mathrm{H} / \mathrm{E}$ stain. Macrophages filled with hemosiderin pigment at the cauda equina level. $\mathrm{G}$ : ganglion cells; $\mathrm{N}$ : nervous tissue; $\mathrm{M}$ : macrophages with hemosiderin.

processes following mitral valve surgery when she was aged 24 years. The coagulation time was checked monthly. She could not tell us if, at the time of the spinal event, the coagulation time was beyond the therapeutic range, as had sometimes occurred. She was not taking any other drug that could interact with Fenprocoumon.

After rehabilitation she was discharged as a wheelchair patient with intermittent catheterisations and enemas at fixed intervals. After her discharge we unfortunately lost contact with her.

\section{Differential diagnosis}

The commonest causes of a cauda equina syndrome (CES) in young people are a herniated lumbar disc (median or massive mediolateral hernia) ${ }^{1}$ or trauma. One to three percent of all herniated disc patients who require disc surgery have a cauda equina syndrome. ${ }^{2}$ The localisation is usually L4-L5 or L5-S1. In older patients a narrow canal is frequently encountered, and in such cases the symptoms usually develop gradually. Tumours, which are found at all ages, represent $1 \%$ of tumours of the central nervous system. ${ }^{3}$ At the level of the CE the main tumours are ependymomas ${ }^{4}$ and schwannomas; other tumours such as meningiomas, lipomas, astrocytomas and metastases are also seen. ${ }^{3,5}$ Iatrogenic lesions of the $\mathrm{CE}$ are another possibility, e.g. after surgical interventions on the lumbar vertebral column, ${ }^{6}$ after epidural anaesthe$\mathrm{sia}^{7}$ and, rarely, after the use of anticoagulants. ${ }^{8,9}$ Dural arteriovenous malformations at the level of the conus medullaris-CE can similarly lead to a cauda equina syndrome through venous congestion, thrombosis, vascular steal or a mass effect with compression. Subarachnoid haemorrhage rarely occurs from dural AV malformations; it is however more often seen with intradural AV malformations. Other rare causes are ankylosing spondylitis, ${ }^{10}$ sarcoidosis, vascular insufficiency at the level of the conus medullaris-CE transition, ${ }^{11}$ and infections.

Spinal epidural haematomas in patients on anticoagulants at the cervical and thoracic levels have been described. ${ }^{12,13}$ As regards haemorrhages at the level of the $\mathrm{CE}$ after the use of anticoagulants, to date we have found only two relevant case reports in the literature, ${ }^{8,9}$ each of which reported acute paraplegia with urinary retention and faecal incontinence. In one patient the haemorrhage was epidural, ${ }^{9}$ in the other it was subarachnoid. ${ }^{8}$ Bewermeyer ${ }^{14}$ describes 126 patients who developed haemorrhage of the central and of the peripheral nervous system during anticoagulant use. Nine patients had spinal cord involvement, mostly epidural and usually thoracolumbar in location. In patients taking oral anticoagulants these complications appeared approximately 2-4 years after the start of the therapy; the coagulation time was usually within therapeutic limits. In those being treated with heparin, the haemorrhage began a few days after the start of such 
treatment. In patients being treated with anticoagulants, haemorrhages are less common in the central nervous system than they are in the urinary, gastrointestinal and respiratory tracts and in the skin. Forfar ${ }^{15}$ states that the use of anticoagulants carries a haemorrhage risk of $4.3 \%$ per treatment year. Others believe that the risk of an intracerebral or spinal haemorrhage is 12 times higher than in the normal population. ${ }^{16}$ According to this last author, in $60 \%$ of the patients who showed a CNS haemorrhage during anticoagulant use, the use of anticoagulants was not justified.

\section{Diagnosis}

The classic triad of a CES, i.e. sphincter/ bladder disturbances, saddle anaesthesia and motor disturbances, possibly with lumbar or lumboischialgic symptoms, is sometimes of acute onset. In such cases there is usually no real difficulty in recognising this severe critical syndrome. In subacute to chronic cases, by contrast, the symptomatology appears much more slowly and therefore the diagnosis is often delayed, sometimes by years.

Patients with a herniated intervertebral disc may be divided into two populations: those with acute and those with subacute symptomatology. ${ }^{2}$ In the latter group sphincter problems develop over several days or weeks and the risk of an initial misinterpretation of the syndrome is high. A purely median herniation may only compress the sacral roots and thus produce no motor or reflex deficits in the lower extremities.

With tumours, pain is the first symptom, and may soon be followed by the other symptoms. ${ }^{3,5,7}$ These may be solely lumbar or solely ischiatiform (uni- or bilateral). Often, however, lumboischialgia is encountered. With tumours there is often pronounced nocturnal pain which is present when the patient is supine and disappears with walking or sitting. ${ }^{3,17}$ By the time the diagnosis is made the symptomatology has usually progressed to the stage where there are also sensory and motor disturbances together with urological and sphincter problems. The localisation of the tumour also determines the speed with which symptoms appear; ependymomas are usually centrally located in the dural sac and only compress the roots after extensive growth, whereas schwannomas are intrinsic caudal root tumours and therefore produce symptoms relatively rapidly before growth becomes destructive. ${ }^{3}$ An intratumoral haemorrhage may occur, giving sudden severe low back pain, ${ }^{4}$ possibly with a CES.

Symptoms of iatrogenic origin, e.g. after surgical intervention, are usually acute and full blown and must therefore be diagnosed and treated immediately; haemorrhage in the $\mathrm{CE}$ gives sudden violent (stabbing) pain with very rapid paraplegia and sphincter deficit. ${ }^{8,9}$

Dural AV malformations at the level of the conus or CE cause progressive symptomatology, with pain as the commonest initial symptom. At diagnosis the classic triad is frequently encountered together with pain. The age at which the symptoms generally appear is around 45 years. ${ }^{18}$ Sometimes an AV malformation can bleed and then the first symptom also is sudden stabbing pain, soon followed by motor and sensory deficits. ${ }^{19}$ These AV malformations are however most often intradurally located.

The number of investigations should be kept to the minimum necessary to reach a prompt diagnosis, permitting suitable treatment. Myelography combined with a CT scan usually gives the greatest amount of information; it is important to go high enough with the myelography, i.e. as far as the thoracolumbar level. ${ }^{17}$ The diagnosis of a herniated disc, compressive process or spinal stenosis can then be easily made. The cerebrospinal fluid obtained at myelography can be examined for elevation of the protein content, and the possible presence of cells. ${ }^{3}$

MRI is a very good alternative investigation and can provide additional important information in many patients. ${ }^{20}$

\section{Therapy and prognosis}

In acute cases (herniated intervertebral disc) the prognosis depends on the delay between diagnosis and surgery. Previously it was believed that surgery within 6 hours was 
necessary for a favourable prognosis, but the requirement seems less stringent. ${ }^{2,21}$ Moreover, with a herniated disc there is no association between the presence of saddle anaesthesia and the recovery of the bladder, ${ }^{21}$ contrary to Scott's opinion. ${ }^{22}$ Motor function of the lower extremities and bladder can still recover after a considerable period of time. ${ }^{23}$

\section{Conclusion}

A patient is described with a rare cause for a cauda equina syndrome; namely haemorrhage at the level of the $\mathrm{CE}$ as a result of anticoagulant therapy. Only an emergency laminectomy with evacuation of the blood immediately after the onset of the paraplegia would have given her any chance for neurological recovery.

The use of anticoagulants must always take into account strict indications and possible contraindications. Interference with the therapeutic coagulation times by interactions with other drugs must be avoided.

\section{References}

1 Tay ECK, Chacha PB (1979) Midline prolapse of a lumbar intervertebral disc with compression of the cauda equina. J Bone Joint Surg Br 61: 43-46.

2 Kostuik JP, Harrington I, Alexander D, Rand W, Evans D (1986) Cauda equina syndrome and lumbar disc herniation. J Bone Joint Surg Am 68: 386-391.

3 Hogenesch RI, Staal MJ (1988) Tumors of the cauda equina. The importance of an early diagnosis. Clin Neurol Neurosurg 90: 343-8.

4 Herb E, Schwachenwald R, Nowak G, Müller H, Reusche E (1990) Acute bleeding into a filum terminale ependymoma. Neurosurg Rev 13: 243-245.

5 Ker NB, Jones CB (1985) Tumours of the cauda equina. J Bone Joint Surg Br 67: 358-362.

6 McLaren AC, Bailey SI (1988) Cauda equina syndrome: A complication of lumbar discectomy. Clin Orthop 204: 143-149.

7 Vandam L (1986) Neurological sequelae of spinal and epidural anesthesia. Int Anaesthesiol Clin 24: 231-255.

8 Nielsen HL, Rohold AE (1989) Cauda equina syndrom under antikoagulationsbehandling. Ugeskr Laeger 151: 1989-1900.

9 Pointud Ph, Uzzan B, Stilhart B (1979) Syndrome de la queue de cheval par hematome epidural rachidien au cours d'un traitement anticoagulant. Nouv Presse Med 8: 4047.

10 Tullous MW (1990) Cauda equina syndrome of longstanding ankylosing spondylitis. J Neurosurg 73: 441-447.

11 Anderson NE, Willoughby EW (1987) Infarction of the conus medullaris. Ann Neurol 21: 470-474.

12 Jacobson I, Maccabe J, Harris P, Dott N (1966) Spontaneous spinal epidural haemorrhage during anticoagulant therapy. BMJ 1: 522-523.

13 Harik S, Raichle M, Reis D (1971) Spontaneously remitting spinal epidural hematoma in a patient on anticoagulants. N Engl J Med 284: 1355-1357.

14 Bewermeyer H, Hojer Ch, Schumacher A, Heiss W-D (1989) Neurologische Komplikationen durch Antikoagulantien und Fibrinolytika. Nervenarzt 60: 268-275.

15 Forfar JC (1979) A 7-year analysis of hemorrhage in patients on long-term anticoagulant treatment. $\mathrm{Br}$ Heart J 42: 128-132.

16 Moskopp D, Brassel F, Ries F (1987) Intrakranielle und intraspinale Blutingen unter Behandlung mit Cumarinderivaten. Klin Wochenschr 65: 781-790.

17 Fearnside MR, Adams CBT (1978) Tumours of the cauda equina. Neurol Neurosurg Psychiatry 41: 24-31.

18 Aminoff MJ, Logue V (1974) Clinical features of spinal vascular malformations. Brain 97: 197-210.

19 Chappel R, de Barsy A, Dua G, Appel B, Herregods P (1988) Spinal angiomas as cause of non-traumatic paraplegia: case report. Paraplegia 26: 425-430.

20 Di Chiro G (1985) Tumors and arteriovenous malformations of the spinal cord: Assessment using MR. Radiology 156: 689-697.

21 Gleave JRW, Macfarlane R (1990) Prognosis for recovery of bladder function following lumbar central disc prolapse. Br J Neurosurg 4: 205-210.

22 Scott PJ (1965) Bladder paralysis in cauda equina lesions from disc prolapse. J Bone Joint Surg Br 47: 224-235.

23 Little JW, DeLisa JA (1986) Cauda equina injury: Late motor recovery. Arch Phys Med Rehabil 67: 45-47. 